\title{
How thick is thick enough?
}

\author{
LD Munro Residue Solutions Pty Ltd, Australia \\ DD Smirk Residue Solutions Pty Ltd, Australia
}

\begin{abstract}
The increasingly stringent regulatory controls and limitations placed on tailings operations to minimise their contaminated and/or operational footprint commonly leads to the simplest of conclusions being reached. That is, to ensure the success of the tailings storage facility (TSF), the density of tailings must be maximised at the point of discharge. The pursuit of higher discharge density began in the 1980s with the development of deep cone thickeners and advanced polymers. From this point, there were additional developments in filtration and centrifugation. However, as technology has developed and various issues endure, it is prudent to ask the key question - how thick is thick enough? While it is generally accepted that a TSF undergoing closure should be of high density and strength to permit flexible closure options, this does not mean this can only be achieved with a high tailings discharge density.

The TSF designer's goal is to ensure alignment between project obligations and constraints to deliver the desired endpoint. Importantly, the cost of tailings management includes not only the TSF but the tailings conditioning technology and, ultimately, closure. Additionally, tailings processing technologies that deliver paste and cake may not be specifically mandated by project constraints.
\end{abstract}

Mud farming, or accelerated mechanical consolidation (AMC) supports a smaller TSF footprint without the need to adopt an expensive pre-disposal processing step. AMC techniques offer the potential to achieve high final densities and strengths through enhanced or continued dewatering and consolidation whilst providing a means of managing many post-placement issues that can occur. This approach can be applied at either the design or adopted within the operating stage and is effective in low-density slurries through to high-density pastes. Accelerated mechanical consolidation evolved from the alumina industry and is now in common practice in many other commodities and industries and is orders of magnitude less expensive than its pre-disposal dewatering counterparts.

Following the tailings dam failure at the Mount Polley TSF in British Columbia, Canada, recommendations from an expert review panel (Brett et al. 2015) include the application of the best available technology (BAT) concept. Australian examples of BAT include dry stacking from filter-pressed tailings at Karara (FLSmidth 2012) and by AMC at various sites, particularly in the alumina industry (International Alumina Institute 2014). This type of approach (Munro 2012) could indicate an appropriate way to utilise BAT without the power, maintenance and capital cost, and availability issues of filters.

Whilst maintaining an appreciation for the required trade-off between the various project constraints, obligations and operational intent, this paper provides a broad examination of some of the simple controls and perhaps unconventional approaches, such as AMC that can best deliver required outcomes in tailings management. Examples are provided of various large-scale tailings management operations that have optimised their operational footprint, lowered operational costs and maintained timely consolidation for a range of discharge densities and regimes.

Keywords: tailings management, accelerated mechanical consolidation (AMC), mud farming, amphirol, best available technology (BAT) 


\section{Introduction}

Many TSF managers observing an excessive filling rate above that of design will immediately look to increasing tailings discharge density, although this may not necessarily be the root cause of the problem being expressed. Rather, it more commonly reflects a symptomatic issue with how the tailings are being managed. This is a common reaction for practitioners caught up in the design condition instead of developing contingencies to ensure operational intent. This can be a difficult issue for the designer to capture, but for the operator, this is a reality. It is possible to address and resolve many dewatering issues through an enhanced operational management system rather than a capital solution. More specifically, having too much water in the discharge stream can have very little impact on how much water remains within the emplaced matrix over a given timeline (Fitton \& Seddon 2013; Reid \& Fourie 2015). More simply, the starting point can have very little to do with the endpoint.

It is therefore important to remember the intent of tailings management in terms of:

- Achieving a desired outcome within a given time period, i.e. it is a process and therefore has independent and dependent variables and can (and should) be controlled accordingly.

- Having a thorough understanding of material properties, how they vary, and their impacts on behaviour.

- Developing contingencies to sustain performance across process variation.

Self-weight consolidation curves continue to be an extremely useful initial step for determining overall behaviour of a tailings stream. However, they also remain one of the most misused tools from designers to practitioners alike as a discharge design point as far up the density curve (as cost-effectively possible) is nominally selected under the assumption that this will then better deliver water return and/or ensure timely consolidation (Bentel 2003).

Self-weight consolidation of tailings is impacted by and largely dependent upon several factors, such as:

- Placement depth - which itself should be determined through beach angle, material properties (particle sizing, mineralogy and surface chemistry), climate and response to potential post-deposition management regimes.

- Liquid phase salinity and chemistry - where crusting behaviour and/or decreased evaporation occurs.

- Water recovery capacity - as impacted by facility design, phreatic surface depth, cycle times and permeability/porosity.

Therefore, consideration of ideal placement depth, impacts of pore chemistry and water recovery limitations (with or without mechanical intervention) is required prior to drawing conclusions or predicting large-scale operational performance outcomes on a given material.

Determining the impacts of these fundamental, inter-related aspects of tailings behaviour and management should not only form the basis of the preliminary design brief, but be fed into modelled scenarios of potential management approaches to ensure that desired outcomes can be achieved and sustained. Put another way, material properties and behaviour should dictate controls that align the design with the intent of the TSF. Once these steps are followed, the TSF is quite simply ready to be managed as the operation's largest tank.

There are very few examples of such an approach to large-scale TSF design and management, but those that follow this process can achieve and sustain desired outcomes at minimal costs, irrespective of discharge density variability (Table 1). However, self-weight consolidation processes remain incredibly slow when compared to accelerated dewatering technologies, and with few exceptions, will always require larger point-in-time operational footprints. It follows that the only way to minimise operational footprint is to enhance the rate of consolidation. 
It is important at this point to not confuse consolidation with dewatering, as one does not necessarily relate to the other. For example, dewatering can be easily delivered through flocculation, but the emplaced material can maintain an extraordinarily high void ratio, or porosity (Yao 2012). Therefore, it is important to determine the in situ bulk density and strength, and not simply measure water return to establish consolidation (Fitton \& Seddon 2013).

To increase consolidation rates, a force must be applied and, if there is any free water within the matrix, it must be able to be removed. Rapid preliminary dewatering of emplaced tailings is highly favoured by many operations for various reasons, mostly related to sustaining a favourable water/process liquor balance, but if porosity endures, then:

- Re-saturation after rainfall is inevitable.

- Consumed volume per tonne of emplaced material is not optimum.

This can, in part, be addressed through subsequent loading from more tailings, although this then imparts a longer drainage pathway for water within the re-saturated profile. A more robust alternative is simply to provide more effective drainage and consolidation through post-deposition mechanical disturbance.

\section{$2 \quad$ Accelerated mechanical consolidation theory}

Accelerated mechanical consolidation (AMC) is the in situ mechanical disturbance of an emplaced material to accelerate the consolidation process (Figure 1). For slurries, it overcomes the effects of hindered settling and expedites water egress from the profile. When applied to highly flocculated or otherwise highly porous material, it collapses pores and rapidly increases density to levels equivalent to filtration or centrifugation. The process is largely delivered by upwards drainage in most materials, although can be evaporation-dominant in some clays. Therefore, the process is not negated by rainfall, nor reliant on evaporation. However, it is best managed by purpose-built equipment to ensure minimal shear (and its commensurate repulping effect). This not only negates the cost-effective application of bulldozers and excavators for large-scale application, but also requires a narrow window of ideal equipment configuration. Over the past few decades, this has led to the now widespread use of slurry-buoyant, screw-propelled machines commonly known as amphirols (or MudMasters ${ }^{\circledR}$ ).
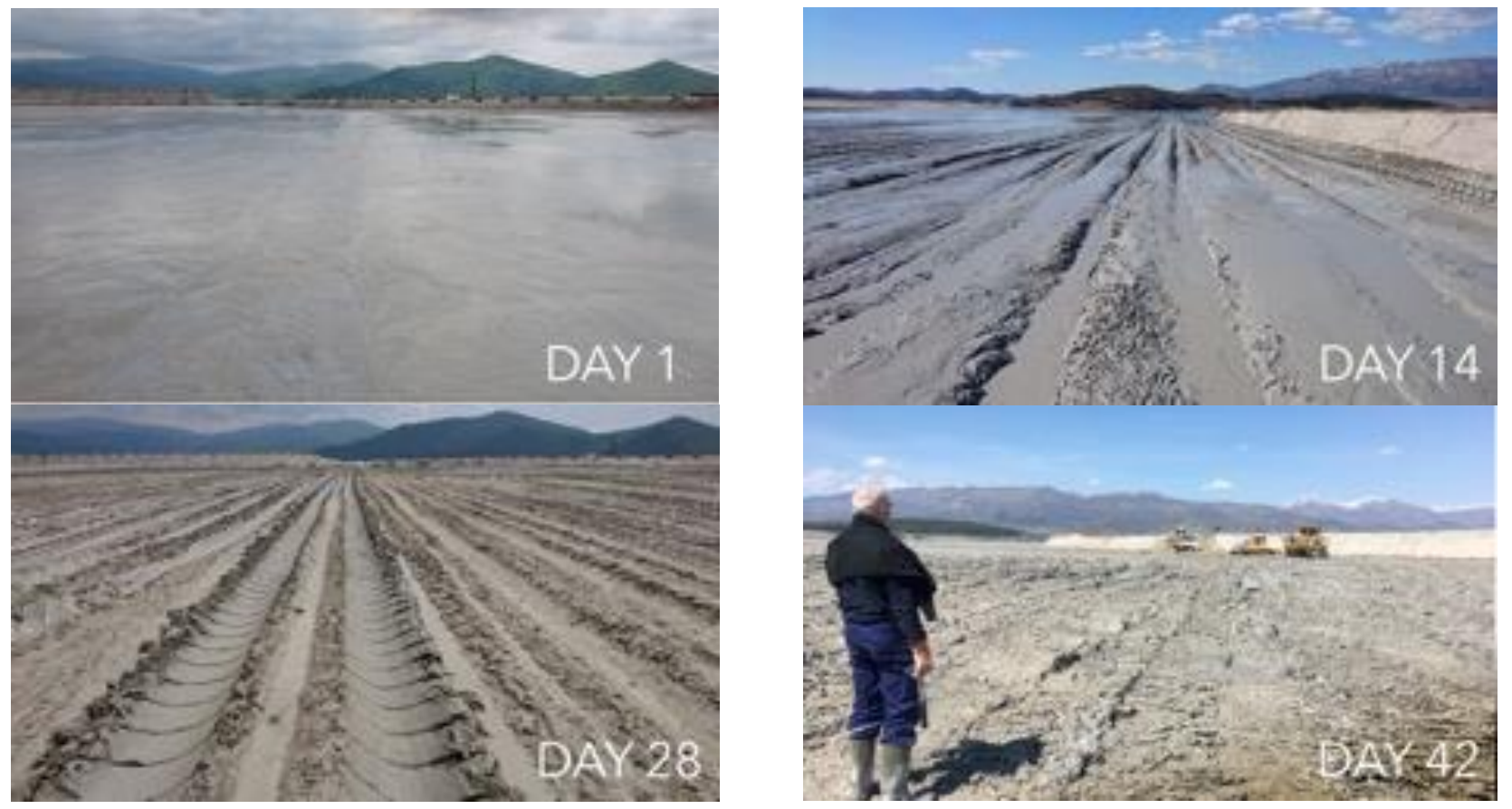

Figure 1 Example of AMC cycle in a clayey-silt TSF 
When designed and configured to suit material properties, AMC regimes achieve incredibly high storage efficiencies (in terms of $\mathrm{t} / \mathrm{ha} / \mathrm{yr}$ ), commonly far above pre-disposal thickening approaches, and with reduced total costs, including closure. This does not infer that AMC is an ideal approach for every application, as each site and operation comes with its own set of constraints, obligations and targets, but it is a viable option for most applications. Conversely, operations that adopt paste or cake disposal, and have no contingencies for maintaining consolidation throughout excursions from the design condition, often require larger operational footprints (in the form of a wet and a dry disposal area) or face downstream construction due to their increased sensitivity to the impacts of extended consolidation periods.

A good measure of TSF performance is that of deposition intensity in terms of tonnes per hectare per year consolidated (noting that a high deposition intensity unconsolidated is of no real value). Table 1 shows that with AMC, low-density disposal regimes rarely exceed 25,000 t/ha/yr, whereas paste can sustain $>60,000 \mathrm{t} / \mathrm{ha} / \mathrm{yr}$. However, although cake disposal operations can theoretically exceed this, in practice this is rarely observed due to various capital constraints on system redundancy, potentially with sufficient area being available for a combined wet/dry regime.

Table 1 provides details of several operations that discharge low-density slurry through to high-density paste and sustain consolidation periods of 4-14 weeks.

Table 1 Range of AMC operations with various operational parameters

\begin{tabular}{|c|c|c|c|c|c|c|c|c|c|c|}
\hline \multirow{2}{*}{$\begin{array}{l}\text { Operation } \\
\text { Co-disposal* }\end{array}$} & \multirow{2}{*}{$\begin{array}{l}\text { A } \\
\text { Partial }\end{array}$} & \multirow{2}{*}{$\begin{array}{l}\text { B } \\
\text { Partial }\end{array}$} & \multirow{2}{*}{$\begin{array}{l}\text { C } \\
\text { Yes }\end{array}$} & \multirow{2}{*}{$\begin{array}{l}\text { D } \\
\text { No }\end{array}$} & \multirow{2}{*}{$\begin{array}{l}\text { E } \\
\text { No }\end{array}$} & \multirow{2}{*}{$\begin{array}{l}F \\
\text { No }\end{array}$} & \multirow{2}{*}{$\begin{array}{l}\text { G } \\
\text { Partial }\end{array}$} & \multirow{2}{*}{$\begin{array}{l}\text { H } \\
\text { Yes }\end{array}$} & \multirow{2}{*}{$\begin{array}{l}\text { I } \\
\text { No }\end{array}$} & \multirow{2}{*}{$\begin{array}{l}\text { J } \\
\text { No }\end{array}$} \\
\hline & & & & & & & & & & \\
\hline $\mathrm{D}_{10}$ & $1.45 \mu \mathrm{m}$ & $2.2 \mu \mathrm{m}$ & $1.9 \mu \mathrm{m}$ & $0.1 \mu \mathrm{m}$ & $0.4 \mu \mathrm{m}$ & $0.9 \mu \mathrm{m}$ & $1.55 \mu \mathrm{m}$ & $1.35 \mu \mathrm{m}$ & $0.35 \mu \mathrm{m}$ & $1.45 \mu \mathrm{m}$ \\
\hline$D_{50}$ & $19 \mu \mathrm{m}$ & $6.5 \mu \mathrm{m}$ & $38 \mu \mathrm{m}$ & $1.2 \mu \mathrm{m}$ & $2.5 \mu \mathrm{m}$ & $6 \mu \mathrm{m}$ & $14 \mu \mathrm{m}$ & $35 \mu \mathrm{m}$ & $4 \mu \mathrm{m}$ & $15.5 \mu \mathrm{m}$ \\
\hline \multirow[t]{2}{*}{$\mathrm{D}_{90}$} & $77 \mu \mathrm{m}$ & $73 \mu \mathrm{m}$ & $175 \mu \mathrm{m}$ & $6 \mu \mathrm{m}$ & $18.5 \mu \mathrm{m}$ & $45 \mu \mathrm{m}$ & $193 \mu \mathrm{m}$ & $75 \mu \mathrm{m}$ & $20 \mu \mathrm{m}$ & $295 \mu \mathrm{m}$ \\
\hline & Quartz & Quartz & Goethite & Goethite & Kaolinite & Kaolinite & Kaolinite & Apatite & Kaolinite & Smectite \\
\hline \multirow{3}{*}{$\begin{array}{l}\text { Dominant } \\
\text { mineral } \\
\text { phases }\end{array}$} & Feldspar & Muscovite & Hematite & Hematite & Hematite & Illite & Illite & Quartz & Microcline & Kaolinite \\
\hline & Illite & Kaolinite & Sodalite & Quartz & Illite & Smectite & Quartz & Calcite & Quartz & Illite \\
\hline & Muscovite & Anatase & Anatase & Sodalite & Quartz & Quartz & Smectite & Smectite & Illite & Quartz \\
\hline $\begin{array}{l}\text { Discharge } \\
\text { density }\end{array}$ & $\begin{array}{l}63 \mathrm{wt} \% \\
1.68 \mathrm{t} / \mathrm{m}^{3}\end{array}$ & $\begin{array}{l}61 \mathrm{wt} \% \\
1.62 \mathrm{t} / \mathrm{m}^{3}\end{array}$ & $\begin{array}{l}55 w t \% ; \\
1.65 t / m^{3}\end{array}$ & $\begin{array}{l}26 \mathrm{wt} \% \\
1.26 \mathrm{t} / \mathrm{m}^{3}\end{array}$ & $\begin{array}{l}42 \mathrm{wt} \% \\
1.37 \mathrm{t} / \mathrm{m}^{3}\end{array}$ & $\begin{array}{l}36 \mathrm{wt} \% \\
1.28 \mathrm{t} / \mathrm{m}^{3}\end{array}$ & $\begin{array}{l}24 \mathrm{wt} \% \\
1.18 \mathrm{t} / \mathrm{m}^{3}\end{array}$ & $\begin{array}{l}27 \mathrm{wt} \% \\
1.22 \mathrm{t} / \mathrm{m}^{3}\end{array}$ & $\begin{array}{l}21 \mathrm{wt} \% \\
1.17 \mathrm{t} / \mathrm{m}^{3}\end{array}$ & $\begin{array}{l}23 \mathrm{wt} \% \\
1.20 \mathrm{t} / \mathrm{m}^{3}\end{array}$ \\
\hline Final & 79 wt\% & $78 w t \%$ & 73 wt\% & 64 wt $\%$ & Trial & $57 w t \%$ & $57 w t \%$ & 64 wt $\%$ & Trial & 56 wt\% \\
\hline Cycle (weeks) & $4-6$ & $4-6$ & $4-6$ & $5-8$ & ND & $6-8$ & $8-12$ & $2-3$ & ND & $8-14$ \\
\hline $\begin{array}{l}\text { TSF intensity } \\
\text { (t/ha/yr) }\end{array}$ & 82,000 & 77,500 & 63,000 & 22,000 & ND & 17,500 & ND & 25,000 & ND & Closure \\
\hline Flocculation & \multicolumn{3}{|c|}{ Little or no flocculent needed } & \multicolumn{3}{|c|}{ Well-flocculated } & \multicolumn{4}{|c|}{ No flocculation } \\
\hline Comments & \multicolumn{3}{|c|}{ Responds very well to $A M C$} & \multicolumn{3}{|c|}{$\begin{array}{l}\text { Easy to manage if controls are } \\
\text { maintained }\end{array}$} & \multicolumn{4}{|c|}{$\begin{array}{l}\text { Difficult/slow to consolidate unless atop a firm } \\
\text { base }\end{array}$} \\
\hline
\end{tabular}

Colour codes - Black: requires enhanced vigilance and control, can be difficult to manage; Grey: more easily managed, some flexibility around control; Blue: no negative impact on AMC or dewatering. ND = no data. ${ }^{*}$ Co-disposal indicates no in-plant separation of fine and coarse fractions.

Therefore, thickening should be executed to the point whereby the water and/or chemistry balance are suitably met, pumping and flow properties are maintained and consolidation is sustained in pace with production. If sufficient area is available for passive/self-weight consolidation, then no further action is required beyond a suitably aligned tailings management strategy (TMS). However, some AMC resource would be advantageous in many cases to re-establish control after enduring process deviations and/or extreme weather events. 
Disposal density will be directly related to the overall water balance of the site. This requires detailed examination of water resources available, the volume of water required to be retained within the process, recirculation clarity targets, expected losses from disposal, process chemistry (if applicable) and various control measures required based on these aspects.

\section{$3 \quad$ Facility design considerations}

Prior to any assumptions being made as to what moisture content a tailings discharge stream should possess, there are several key criteria that need to be appraised within the overall operation's design brief to best ensure a cost-effective and sustainable system is chosen for the tailings management:

- Plant location - including topography, availability of water for processing and proximity to a suitable TSF site.

- Geotechnical considerations - including static liquefaction potential.

- Available area for tailings storage - too large or too small will both have enduring impacts in addition to room for expansion and cost of acquiring additional land.

- Surrounding land uses, proximity to private property, etc.

- Licence to operate constraints - such as ultimate design height and enduring containment obligations (including zero discharge sites) - intended closure requirements, sequential land use, how will it be re-incorporated back into the local landscape?

- Budget constraints - in terms of both capital and operational expenditure.

Importantly, these aspects simply provide the boundaries of the design brief, and generally cannot in themselves be used to justify a management strategy, let alone a disposal density.

Once a suitable area has been designated and operational constraints identified, it is then time for a detailed assessment to align flow rates with material behaviour and desired outcomes. Although all refineries and processing plants have a degree of recirculation or flow-buffering capacity (albeit limited), very few take advantage of this design aspect to stabilise residue flows. Additionally, orebodies are not homogenous and TSFs are highly dynamic environments, so the facility must be designed with sufficient redundancy in terms of area, and flexibility in terms of available cells and discharge spigot network to absorb variation and sustain performance and location of water collection points. Importantly, both flow rates and material properties will vary in short and long-term cycles, but the desired outcome from tailings management will not, which is why contingencies need to be designed into the management system.

\section{$4 \quad$ Facility operation considerations}

Audits of operations achieving poor consolidation performance regularly show that the TMS for the operation does not possess sufficient scope to accommodate sustained performance across variation, potentially with new learnings rarely captured and updated versions yet to be drafted. The TMS should not only detail how the facility is supposed to be operated, based on controls and activities proven to deliver a desired outcome or endpoint, but also detail contingencies for preventing and/or recovering from periods of sub-target performance.

Having a well-written and suitably resourced TMS better ensures that consistent outcomes are achieved and that a single-point source of guiding information is running the site. This is in contrast to simply having a few skilled field staff that are relied upon to initiate contingencies based solely on experience. The issue with the latter approach is not that the most skilled operators are necessarily wrong, but more of the variation in performance when situations arise in their absence. Put another way, the TMS should ultimately run the area, not the personnel. Adherence to the TMS is also a critical part of dam safety requirements as the TMS will ensure compliance with the critical TSF design assumptions. 
Regular auditing of the TMS is required to reconcile material properties and flows in addition to its suitability against an ever-changing site resource base and TSF morphology. Additionally, as the TSF is a permanently dynamic environment, the tried and proven methodologies applied to deliver the required outcomes need to be adjusted with time to maintain performance throughout the life of the facility. Therefore, it must evolve as the operation matures and be reassessed as production increases or conditions change.

Accelerated mechanical consolidation provides a means to not only keep consolidation in pace with flows, but bridge process variation through increased resource application intensity.

\section{$5 \quad$ Process integration}

As indicated earlier in this paper, the TSF and its associated TMS must be integral components of the overall operational design process. If this is not done prior to active operations, then problems will be quickly realised soon after commissioning, usually in the form of rapid volume consumption and/or poor water recycle. However, process integration entails far more than simply stating a desired discharge density that lies within the system's capacity and then expect the desired endpoint to always be achieved. It must be a holistic approach to ensuring the endpoint is achieved irrespective of discharge fluctuations or climatic conditions. This does not infer that a target discharge density is not important. It is very important, but the TMS must have contingencies to absorb process excursions and sustain the design target.

One problem often encountered is the single-point discharge density target, which nominally reflects the upper threshold of the system. More rarely observed is the far more sustainable approach of having a target range that has an upper threshold slightly below the system's capacity, with a lower value that is also amenable to sustained management and performance.

As an example of best practice, the upper threshold for slurry and paste should maintain pump transport and still readily flow so that it can be emplaced evenly into the TSF, whilst the lower threshold also maintains a suitable beach angle.

For filtration and centrifugation, sufficient system redundancy is required to ensure sustained performance within the target range of performance, with due consideration of required contingencies to sustain transport and post-deposition management when below the lower threshold. This can be addressed through the provision of additional area for wet disposal with or without AMC resources.

A further advantage of managing the TSF as a tank is that the filling rate/surface area ratio is far superior to any in-process unit. This in turn creates a more robust management opportunity in the field so long as placement depth is adhered to. When this is not adopted or indeed, understood, the common reaction by field staff is to simply abandon any attempts at control until the perceived design case is reinstated. However, any abandonment of key controls will have an enduring consequence in terms of consolidation.

\section{$6 \quad$ Case studies}

Several examples of low-density slurry, thickened slurry and paste, and cake discharge operations are presented in the following sections, with passive and active (AMC) approaches, seeing why they are successful and how their management systems are aligned to suit each site.

\subsection{Low-density disposal}

It is commonly overlooked that low-density slurries are very easy to sustain and cheap to pump over long distances, although increasing volume and distance eventually become key constraints. The usual introduction to low-density disposal suggests high risk operation due to poor consolidation, groundwater risk, high operational costs due to poor volumetric filling efficiency and/or downstream construction in conjunction with extended (and potentially extensive) closure campaigns (e.g. Netherton 2017). Such a summary is enough to sway most designers and operators towards anything but low-density disposal, irrespective of project constraints. 
However, as indicated previously, disposal density does not necessarily have a direct link to final outcome. The aforementioned proposed outcomes are examples of poor and/or inconsistent operation, and again highlight the need for a robust TMS and suitable contingencies.

It is true that lower discharge densities impart much higher flow rates and therefore fill areas more quickly, are more sensitive to placement depth and can be far more reliant on evaporation (sometimes irrespective of $A M C$ ), can also segregate at or near the point of discharge and require a larger point-in-time TSF area. Therefore, these factors must be considered within the TSF design and TMS development stages to ensure placement depth is strictly adhered to and field staff are adequately trained and resourced to deliver the required management regime. However, these aspects of low-density disposal are well known, mostly short-term and of no consequence so long as such sensitivities are understood, suitable controls are defined and maintained, and (if required) subsequent in situ management is enacted. More specifically, a fast-flowing, low-density slurry will usually possess a lower beach angle and require more vigilance to manage to ensure performance targets are achieved. The perceived additional management effort applied to ensure a low-density discharge regime is consolidated in pace with production should be readily comparable to the costs of alternative thickening, transport and/or in situ management options.

Another important point is that of the material's settled density, which may be far higher than its required transport density and therefore allow significant in situ thickening soon after emplacement. However, this approach requires increased vigilance on all aspects of water management, including placement depth and location control to ensure decant feed. Again, this simply enforces the TSF to be managed as another tank in the process that should be treated with the same discipline as any other unit process.

If low-density disposal cost effectively matches all requirements within the water (and/or chemistry) balance, licence to operate constraints and obligations and contingencies are in place to ensure these flows are sustained and consolidation keeps pace with production, then there is little justification for pursuing thickening.

\subsubsection{Ore beneficiation}

An ore beneficiation plant located in a tropical climate with $>2.20 \mathrm{~m}$ of annual rainfall discharges $6.5 \mathrm{M} \mathrm{t} /$ year of low-density slurry at an average of $25 \mathrm{wt} \%$ solids (bulk density of $1.245 \mathrm{t} / \mathrm{m}^{3}$ ). The TSF is 400 ha in area and divided into four cells, but only possesses a rudimentary TMS. Its production rate, large available footprint, benign residue and close proximity between the plant and TSF all bode well for low-density slurry disposal. However, in recent years, increased production has led to poor water return and wide-ranging stage construction budgets and timelines are enforcing an optimised TMS.

Controlled depth tailings placement was never adopted and areas were nominally poured to simply fill an entire cell stage in an arbitrary, pre-determined sequence. Once construction moved to a filled area, various recovery works were enacted as required to expedite consolidation prior to each new perimeter embankment construction campaign.

This cycle was repeated for several decades until a controlled depth placement campaign with AMC was implemented. This quickly transitioned the site to the scenario whereby all emplaced material could be consolidated within six weeks of placement and one cell was permanently available for construction with an already fully consolidated perimeter. This required an increase in operational expenditure (<AUD1.30/t dry), but no capital and no complicated or unplanned remediation works are required prior to construction.

\subsubsection{Mineral processing}

A relatively new mineral processing operation produces around $0.25 \mathrm{M} \mathrm{t} / \mathrm{year}$ of highly saline $(>40 \mathrm{~g} / \mathrm{L})$ tailings discharged into two dedicated TSFs at around 12-17 wt\% solids $\left(1.13-1.18 \mathrm{t} / \mathrm{m}^{3}\right)$. TSF design documents suggest self-weight consolidation to deliver an in situ bulk density of $>1.72 \mathrm{t} / \mathrm{m}^{3}$ within one 16 ha TSF, but there was no supporting TMS to address how this was to be best delivered, nor was a range of discharge chemistries/salinities addressed. 
The complex chemistry of the residue stream in addition to its fine particle size distribution (PSD) promotes water retention within the profile, to an extent whereby the average profile bulk density of the first impoundment equates to $1.53 \mathrm{t} / \mathrm{m}^{3}$ after three years of operation. Additionally, if the surface is left fallow, a crust can form, but only to a depth of around $200 \mathrm{~mm}$ between wet seasons.

Filtration has been costed for the operation, but the remote location in addition to diesel-electric power requirements precluded this as a preferred option. Additionally, point-of-discharge flocculation has been adopted, but this has been poorly executed in so far as a single dose point supplying an entire TSF, even though supporting technical documents state a dosing point every $400 \mathrm{~m}$.

Therefore, low-density disposal was not the issue. No contingencies to sustain performance across a range of chemical conditions, poor placement control and no post-deposition management all contributed to the unsustainable condition of the TSF. More simply, a detailed TMS containing activities proven to achieve desired outcomes across a range of conditions was required.

The operation has adopted AMC to bridge the gap between consolidation theory and practice and ensure outcomes are achieved within required timeframes and area.

\subsection{High-density disposal}

There are many justifiable arguments for high-density disposal; for example, when water resources are more scarce, or strict process chemistry balance is required, and/or point-in-time disposal area is limited. Many tailings respond very well to thickening (particularly with recent advances in flocculation), with discharge densities exceeding $1.65 \mathrm{t} / \mathrm{m}^{3}$ observed in many operations and commodities. However, whilst thickening up to the material's pumping limit may benefit the short-term water balance, consolidation may still require prolonged periods depending on placement controls and TSF design and management. More specifically, having less water in an unconsolidated profile is of limited benefit for upstream construction and the added expenditure of positive displacement pumps and associated high-pressure pipelines must be considered.

Additionally, if high-density disposal is chosen, then the TSF must be designed and managed to accommodate its properties. As previously mentioned, there is little advantage to emplacing a thickened material into a large impoundment if it possesses poor flow characteristics. Variable placement depth can lead to a range of plants and approaches being required to spread and/or otherwise manage the tailings to ensure timely consolidation. Conversely, tailoring the TSF to accommodate limited flow properties after operations commencement can lead to a complex array of disposal areas, requiring much larger civil construction budgets to maintain.

Accelerated mechanical consolidation was originally derived from thickened slurry and paste disposal operations that discharged caustic red mud suspended in Bayer process liquors at up to $60 \mathrm{wt} \%$ solids. Deep or otherwise variable placement depth quickly leads to upper surface crusting and prolonged liquor entrapment in red muds. Additionally, frequent re-pours atop of unconsolidated material is a perfect way to ensure prolonged liquor entrapment and extend consolidation to several years. Therefore, paste disposal in itself is of little benefit to tailings management without AMC and a suitably aligned TMS.

Accelerated mechanical consolidation was quickly adopted as a highly advantageous approach for an industry that had much to gain from expediting liquor return (commensurate with limiting carbonation), and is why AMC is currently used on $>40 \%$ of the global alumina industry's red mud facilities. However, AMC is just another tool in the process loop, analogous to the rake in a thickener, and only if the tool's design is appropriate for the material and its use aligns with flow rates and required targets will desired outcomes be achieved.

\subsubsection{Coarse tailings - neutralised/benign}

It may be surprising that a high-density clayey-silt disposal regime would experience issues with timely consolidation. However, this is exactly the case for many operations and commodities that have incredibly high disposal loads and limited footprints. The first operation highlighted here has been undertaking downstream embankment construction for several decades, and has now approached the extent of its lease boundary. 
With no opportunity to extend their operational footprint out, the operation is now forced to go up. This now transitions the operation to the scenario whereby consolidation in pace with production is mandated, and the operational footprint will now reduce with each wall raise.

An available surface area/flow ratio indicated that $1,100 \mathrm{~mm}$ pours are sustainable with 45 day cycles. This is therefore the working window for an AMC regime. Importantly, although shallower pours are also possible in theory, this then mandates $24 / 7$ valve observation. This was viewed as both unrealistic and unnecessary for the site, and so the increased depth was adopted along with suitably configured AMC equipment deployed to match this depth and its subsequent settled density.

The site now operates $14.5 \mathrm{M} \mathrm{t}$ /year on 180 ha and is consolidating its perimeter embankment areas in pace with construction timelines. However, the TMS is yet to be updated and AMC is not yet a component feeding into the long-term plan. Importantly, perimeter farming can provide a false sense of efficiency and security to operations as the facility then develops two distinct rates of rise. Under such a scenario, it is inevitable that the inboard areas eventually overtake the farmed perimeter, and therefore AMC works will need to be expanded in the coming years.

Given the flow rates and available area for this operation, low-density disposal could not possibly be considered. Similarly, cake disposal would be economically prohibitive for the site from both capital and operational expenditure perspectives. Additionally, high-density paste disposal with self-weight consolidation does not ensure timelines and outcomes, therefore AMC was the best choice to complement the operation.

\subsubsection{Coarse tailings - complex chemistry}

A similarly large-scale operation discharges $10.5 \mathrm{M} \mathrm{t}$ /year of tailings at 54-58 wt\% solids into a partitioned 190-225 ha TSF. Previous management was simply to fill a stage as fast as possible under the logic that this would best provide sufficient time for self-weight consolidation to deliver the required density. However, this simply led to upper surface crusting and enduring process liquor entrapment.

After several protracted campaigns of emplaced tailings extraction and re-handling to deliver suitable material for upstream embankment construction, a new approach was eventually adopted which executes strictly controlled placement to then allow an optimised AMC regime. This has led to all emplaced residue being consolidated in pace with production and enhanced process liquor return.

Again, minimising the entrained tailings liquid phase was advantageous for the process chemistry, but did not ensure or enhance timely consolidation in the field. Furthermore, the design condition was for a 58 wt $\%$ solids discharge stream, and poor consolidation was simply blamed on this somewhat arbitrary target not being sustained. The new TMS for the site requires a sustainable discharge range of $53-58 \mathrm{wt} \%$ solids that is readily managed by the AMC fleet, irrespective of season.

\subsection{Cake disposal}

The business case for filtration and centrifugation is easily justified in many chemical processes, as retention in-process can provide many savings in terms of energy and reagent recycle efficiency. Such are the savings that can be realised, that some operations filter residue simply to retain their process liquor, then re-slurry with waste water for disposal (e.g. Patel \& Pal 2015). Additionally, mineral extraction liquors are by their very nature not substances that align well with the natural environment, and therefore retention, neutralisation or minimisation is required, or at least considered best practice in most jurisdictions.

Water scarcity and limited available TSF footprint are other commonly encountered driving forces for adopting cake disposal, along with proximity of the TSF to the processing plant. It is also easily determined if pumping and slurry disposal are economically viable for a given site.

However, as much as pumping, pipework and discharge spigot network configuration are key aspects of slurry and paste disposal, so are conveying, trucking (or training), in addition to spreading, ploughing and compacting for cake disposal. Thus, consideration needs to be given to the size and complexity of the tailings transport and management fleet required to deliver the desired outcome. For trucking operations, this can 
also lead to complex risk assessments as $>10,000$ vehicle movements per month are easily realised for a $24 / 7$ operation with several million tonnes of residue per year.

Additionally, there will always need to be a contingency plan for off-spec material, as most plants have a limited capacity for extended withholding or recirculation of residue. This is evident in many plants that have full-scale residue filtration systems with clearly defined cake and slurry disposal ponds as a quick tour of Google Earth ${ }^{\circledR}$ can easily provide. Consistent cake disposal can be sustained if sufficient system redundancy is built into the process. Although, this is a more likely adopted approach for product and not waste circuits.

Cake disposal still requires post-deposition management to deliver consolidation (Munro et al. 2014), and perhaps more importantly, avoid re-saturation. Again, a low moisture content is not an indicator of a bulk density, and most cake disposal operations require spreading, ploughing and final compaction.

\subsubsection{Mineral processing operation}

An initial design brief for an arid climate operation required zero-discharge and allocated a 900 ha TSF. However, the TSF was located $>30 \mathrm{~km}$ from the plant and all possible routes crossed public land and state infrastructure. Although the tailings possess a fine PSD and production was forecast at above $2.4 \mathrm{M} \mathrm{t} /$ year, cake disposal was by far the most favourable business case, particularly in light of the availability of a railway line between the plant and the TSF.

However, as construction progressed, the rail transportation option was abandoned and trucking was substituted. This caused a massive increase in OPEX and led to the additional issue of sustaining residue handling through off-spec events. To address this, additional processing units were incorporated into the filtration circuit and a change in truck design was adopted. Although these steps represented a significant increase in capital expenditure, no other disposal option could meet the strict environmental guidelines in terms of risk for enduring containment within the pristine environment. A key point of consideration was how dust could be contained if a larger footprint was in fact utilised?

This was not a case of cake for the sake of cake, but was a clearly defined business case in terms of licence to operate and strict state agreements.

However, many existing cake disposal operations do not have the same stringent pre-construction guidelines to ensure sustained operation across a range of conditions.

\section{Conclusion}

Low-density slurry, high-density slurry and paste and cake disposal regimes are all equally valid approaches to tailings management so long as the adopted approach aligns with the various operational performance and legislative obligations for the site. Designers need to consider the most suitable approach that can sustain performance throughout short and long-term variance and not simply pursue a paste or cake option without due consideration to more cost-effective approaches that may deliver equivalent performance. Accelerated mechanical consolidation remains an extremely useful tool to bridge process variance and desensitise operations to self-weight consolidation. Similarly, other forms of post-deposition management remain valid for cake disposal regimes to best ensure rapid transition to the desired density and strength. Irrespective of disposal density, commodity or scale, the TSF and TMS must align and be fully integrated into the plant's process with tailings management given the same discipline as all other unit processes.

The key point of this paper is to demonstrate that the discharge density of tailings, whether low-density slurry or cake, is not the key limiting or determining factor to achieving a desired outcome and that the industry should diversify their approach to TSF design and operation to ensure suitable equipment and/or contingencies are in place to sustain performance throughout all operational variation. 


\section{References}

Bentel, G 2003, 'Above ground disposal', in RJ Jewell, AB Fourie and ER Lord (eds), Paste and Thickened Tailings: A Guide, Australian Centre for Geomechanics, Perth.

Brett, D, Longey, R \& Herza, J 2015, 'Abracadabra - the disappearing tailings dam', Proceedings of the 2015 ANCOLD Conference: Contemporary Challenges for Dams, Australian National Committee on Large Dams, Hobart.

Fitton, TG \& Seddon, KD 2013, 'Paste and thickened tailings - myth busting and clarification', in RJ Jewell, AB Fourie, J Caldwell and J Pimenta (eds), Proceedings of the 16th International Seminar on Paste and Thickened Tailings, Australian Centre for Geomechanics, Perth, pp. 37-46.

FLSmidth 2012, World Class Tailings Technology for Karara, FLSmidth, Perth, viewed 16 February 2018, http://flsmidthminerals.com/ 2012april/2015/12/29/world-class-tailings-technology-for-karara

International Alumina Institute 2014, Bauxite Residue Management Best Practice, International Aluminium Institute, London, and European Aluminium Association, Brussels.

Munro, LD, White, RW \& Smirk, DD 2014, 'Post-deposition management - the next step in paste and thickened tailings management', in RJ Jewell, AB Fourie, PS Wells and D van Zyl (eds), Proceedings of the 17th International Seminar on Paste and Thickened Tailings, InfoMine Inc., Vancouver, pp. 403-416.

Munro, LD \& Smirk, DD 2012, 'Optimising bauxite residue deliquoring and consolidation', Proceedings of the 9th International Alumina Quality Workshop, AQW Inc., Perth.

Netherton, DE 2017, Conventional Disposal vs. Thickened Tailings Disposal, Tailings Management Systems, South River, viewed 16 February 2018, http://www.thickenedtailings.com/profile.html

Patel, S \& Pal, BK 2015, 'Current status of an industrial waste: red mud an overview', International Journal of Latest Technology in Engineering, Management and Applied Science, vol. IV, no. VIII, pp. 1-16.

Reid, D \& Fourie, AB 2015, 'The influence of slurry density on in situ density', in RJ Jewell and AB Fourie (eds), Proceedings of the 18th International Seminar on Paste and Thickened Tailings, Australian Centre for Geomechanics, Perth, pp. 95-106.

Yao, Y 2012, 'The effect of flocculent on the geotechnical properties of mature fine tailings', in D Sego, GW Wilson and N Beier (eds), Proceedings of the 3rd International Oil Sands Tailings Conference, Oil Sands Tailings Research Facility, Calgary, pp. 391-398. 
